\title{
INTERNET OF THINGS AND SOCIAL MEDIA: TOOLS OF A SUCCESSFUL INFORMATION ORGANIZATION
}

\author{
Vlado Majstorovic \& Kresimir Rakic
}
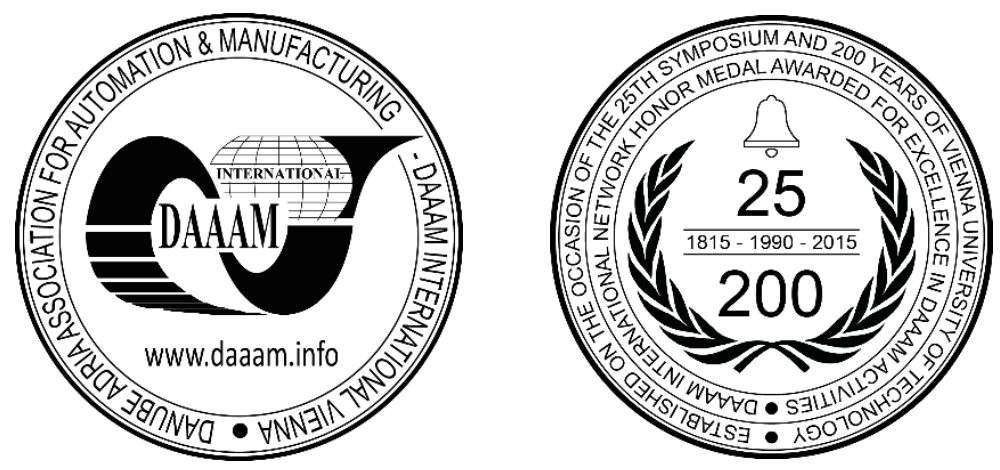

This Publication has to be referred as: Majstorovic, V[lado] \& Rakic, K[resimir] (2017). Internet of Things and Social Media: Tools of a Successful Information Organization, Proceedings of the 28th DAAAM International Symposium, pp.0295-0298, B. Katalinic (Ed.), Published by DAAAM International, ISBN 978-3-902734-11-2, ISSN 1726-9679, Vienna, Austria

DOI: $10.2507 / 28$ th.daaam.proceedings.040

\begin{abstract}
Information technology represents a conglomerate of microelectronics, computers, telecommunications and software, which enable input, processing and distribution of information. It is the fundamental tool of many organizations' strategies and key factor that enable their efficient work and their competitiveness in the market. Modern organizations are so dependent on information processes, flow of information and the application of modern technologies that we can legitimately call them "information organizations". These organizations arise from the traditional ones by application of business processes reengineering and they introduce the new principle of the communication range instead of the classic principle of the control range. Technology of the Internet of Things and communication through social media are two exciting new directions, that can contribute to more successful collection and management of data, important for the organization. Organizations need to adapt to these new technologies for an effective approach to creating, sharing, and analysing information. This paper emphasises the benefit that inclusion of these new technologies brings to the information organization and the potential need for organizational adaptation to the new reality.
\end{abstract}

Keywords: Modern technologies; Information organization; Social media; Internet of Things

\section{Introduction}

Proper functioning of the organization and achievement of the desired goals is possible only through the contribution of the information system that provides the raw material and the information necessary to establish the goals, tasks, powers and responsibilities of the management. Information represents essential support in decision-making and communication [1].

Most of the employees, at their workplace, are exposed to some form of information technology (IT). IT represents a conglomerate of microelectronics, computers, telecommunications and software, which enable input, processing and distribution of information. IT is the fundamental tool of many organizations' strategies and key factor that enable their efficient work and their competitiveness in the market. It helps in gathering data and creating information that is useful in making business decisions. New IT enables today's personal computers to use multiple media such as sound, text and video, as well as access to remote databases, leading to a revolution in the joint work of people with the aim to create a successful organization. 
The most significant changes in work and business that are brought by the IT are: work in groups, the ability to work outside the office, the creation of non-hierarchical organizations and the outsourcing of a part of business to external organizations. IT today becomes a strategic element in the development of the organization and the society in general, and they are also transformed into one of basic management resources. Today, the organization from the point of view of modern management, becomes so dependent on information processes, flow of information and the application of modern technologies that it can rightly be called an "information organization".

The information organization arises from the traditional one by application of business processes reengineering. This organization introduces the new principle of the communication range instead of the classic principle of the control range. This means that unnecessary management levels are eliminated, i.e. workers who do not work but coordinate others work, and those who actually produce remain. The supervision function is partially performed by the IT. The information flow is circular - information is shared between subordinates and superiors. Also, they travel faster and easier, without unnecessary paperwork. Responsibility and initiative are brought down to "lower" levels.

Information-based organizations need a large number of expert staff who can work with an information system (transactional system, decision support system and/or expert system). The individual takes responsibility for his job and does it the way he knows, without interruption of his superior. The care for human capital is handled within the Human Resources Department.

The information organization is trying to respond as quickly as possible to the needs of its clients. They bind people for a particular client and always have to be available to them. This is helped by an information system for providing and exchanging information about the client and reporting to the supervisors about the performance of the business. Since information organizations manage knowledge, a new type of manager - Chief Knowledge Officer is provided to ensure knowledge development. The increasing reliance on technologies in contemporary organisations makes it vitally important to increase the capacity to plan for and manage technological change [2].

Two exciting new directions, that can contribute to more successful collection and management of data important for the organization, are the technology of the Internet of Things (IoT) and communication through social media. In the following chapters, we will discuss the features of these two innovations in the traditional way of using data in an organization.

\section{Internet of Things in modern organization}

The pace of technological progress in today's industrial society is essentially dictated by microelectronics and computer technology. Computers are becoming much smaller, inexpensive, last even longer, and part of everyday items: a table, our clothing, our environment and even our bodies can become computers and connected to Internet [3].

Using of sensors to monitor the condition of equipment and the work environment is not a novelty. However, connecting these sensors with the Internet and insights into the collected data revolutionizes almost all imaginable industries, from healthcare and retail to transportation and manufacturing. This new technology, technology of the IoT, even changes the way cities work. IoT supplies organizations with systematic insights to encourage smarter decisions and work processes, and to achieve better results.

The basic concept of the IoT is that everyday objects can be equipped with identifying, sensory, network and process capabilities that will enable them to communicate with each other, as well as to communicate with other devices and services over the Internet in order to achieve some useful purpose. IoT represents an evolution of the use of existing technologies, such as RFID technology, sensor networks, device communication, etc., in terms of number and type of device, as well as networking of these devices over the Internet.

The potential benefits of the IoT are almost unlimited and new applications are being developed every day. There are a number of different sensors that can be used in IoT applications, such as [4]:

- Sound sensors,

- Machine vision sensors and optical ambient light sensors,

- Light sensors,

- Acceleration and tilt sensors,

- Position and presence sensors,

- Movement, speed and shift sensors,

- Moisture, temperature and humidity sensors,

- Leakage and level sensors,

- Electric and magnetic sensors,

- Other sensors. 
According to Cisco forecasts, IoT will make up to 500 billion devices connected to the Internet by 2030, which will ultimately improve productivity, create new business models, and generate new revenue streams [5].

Organizations that are willing to replicate the success of using the IoT must be aware of the fact that each initiative will consist of three steps [6]:

- In the first step, the organization should figure out the way to use IoT data about clients, associates, partners, and others. This step, commonly, consists of simple analysis and standard projects that are common within the industry as they bring clear added value.

- In the second step of implementation of the IoT, collected data begins to produce information that helps organizations launch projects that will differentiate them from competitors and provide them with unique features.

- In the final step, the organization has the opportunity to use its investment in IoT to develop new, exciting projects that change its business model. At this stage, organizations can really be separated from the competition.

In a modern company, employees can carry radio frequency identification (RFID) tags so they can be easily located in a case of emergency evacuation, and the management can identify potential bottlenecks in the work process.

For productivity analysis of employees, it is possible to use the cameras together with the software for tracking and analysing the video. The system can be linked to whiteboards, and the facility can be equipped with televisions that will provide work information about work team productivity to identify potential areas for improving the process.

Public security in the organization's facilities is another part in which IoT can play an important role. Capabilities of personal identification, audio and video analytics including face recognition and license plate readers, associated with cloud-based reporting systems will help prevent crime.

\section{Potential benefit of using social media in organization communication}

While there is still a certain caution on their application, the new media also affects the traditional media and the behaviour of information media users within organizational communications. As with traditional media channels, new media have their own advantages and disadvantages, and careful consideration is needed to optimally exploit their capabilities [7].

Using social media, public opinion communicates itself and reaches a significant targeted audience. In this way, the classical target audience of the organization is activated, ant it is not satisfied with just receiving and consuming information, but it also provides its contribution to data interpretation and commentary. Using social media also changes internal communication within the organization. By communicating through social media, employees contribute to the company public image [8] and create a feeling of belonging to the group. Outside the organization employees are perceived as real ambassadors of the company.

The challenge for the organization is to find ways to make their traditional communication structure more flexible and to enable successful integration of social media in it.

In order to determine the position of social media in communication within an organization, it is necessary to emphasize their particularities. Social networks represent a set of Internet applications based on the ideological and technological principles of Web 2.0 and enable the creation and exchange of user-generated content [9]. Web 2.0 is defined as a business revolution in the computer industry caused by moving to the Internet as a platform and attempting to understand the rules for success on this new platform [10]. We can say that Web 2.0 allows the transition from a reading web towards writing/reading web, a web filled with user-generated content which allows the usage of web application. Web 2.0 tools give communication professionals the opportunity to become more and more innovative and creative and add increasing value to the business [11].

Social media represents, so called, "me" communication, challenging communicators to use them to stimulate employee engagement, provide relevant information, and discover staff attitudes, insights and problems. Once students' informal tool has become a robust platform that connects billions of people around the world every day [12]. They represent new electronic communication channels based on the virtual environment: blogs, podcasts, wiki encyclopaedias, chat rooms, discussion forums, RSS feeds, web sites, social networks and other media that encourage dialogue. It is important for modern organization to find a way to fully exploit the vast potential of these modern communication media. 


\section{Conclusion}

The amount of data, collected and shared within the organization, is getting bigger. In the planning of information infrastructure, it is necessary to look at it several years in advance, and it is almost impossible to estimate the future needs for the data space that organization will need. It is therefore important to find scalable and flexible storage solutions that can grow along with the deployment level of IoT. Cloud-based storage, whose size can easily be increased or reduced, is one of the possible solutions to this problem.

Social media has undergone substantial evolution in the new millennium. Its technology development will continue and soon it will include new technologies, such as artificial intelligence, virtual reality, and augmented reality. By developing social media opportunities, their potential for contributing to effective organizational knowledge management is growing. Organizations need to adapt to the new social media capabilities for an effective approach to creating, sharing, and analysing knowledge.

\section{References}

[1] Kurtuhuz, A. M.; Radu, D. L.; Anghel, A.; Zahiu, C. E.; Salisteanu, I. C.; Udroiu, I. N. \& Dumitrica, M. A. (2013). The Information as the Essential Element in Communication Management, Chapter 34 in DAAAM International Scientific Book 2013, pp. 619-628, B. Katalinic \& Z. Tekic (Eds.), Published by DAAAM International, ISBN 9783-901509-94-0, ISSN 17269687, Vienna, Austria, DOI: 10.2507/daaam.scibook.2013.34

[2] More, E., \& Laird, R. K. (1983). Modern technology and organisational communication implications for management, Journal of information science, Vol. 4-5, No. 7, pp 169-183.

[3] Buchmeister, B.; Leber, M.; Palcic, I. \& Vujica-Hercog, N (2013). Future Development Trends and Challenges in Production and Social Systems, Chapter 04 in DAAAM International Scientific Book 2013, pp. 111-132, B. Katalinic \& Z. Tekic (Eds.), Published by DAAAM International, ISBN 978-3-901509-94-0, ISSN 1726-9687, Vienna, Austria, DOI: 10.2507/daaam.scibook.2013.04

[4] Al-Fuqaha, A., et al. (2015). Internet of things: A survey on enabling technologies, protocols, and applications, IEEE Communications Surveys and Tutorials, No. 17, pp. 2347-2376.

[5] https://www.cisco.com/c/r/en/us/internet-of-everything-ioe/internet-of-things-iot/index.html, (2017). Cisco, Cisco Internet of Things, Accessed on: 2017-08-27

[6] IoT Whitepaper: Building a data-driven future, (2016). CDW, Available from: https://www.cdw.com/content/dam/CDW/resources/solutions/data-center/networking/iot-building-a-data-drivenfuture.pdf, Accessed on: 2017-08-27

[7] Berger, B. K. (2008). Employee/Organization communication, Institute for Public Relations, The science beneath the art of Public Relations, Available from: http://www.instituteforpr.org/topics/employee-organizationalcommunications, Accessed on: 2017-08-27

[8] Julich, T. (2012). Kommunikationskanal, aber mit anderen Spielregeln. BMV Group, Ein KommunikationsManager, PR Romania, Available from http://www.pr-romania.ro/articole/pr-20/1385-thorstenjulich-bmw-group-social-media-un-canal-de-comunicare-dar-cu-alte-reguli-de-joc.html, Accessed: 2017-08-27

[9] Kaplan, A. M. \& Haenlein, M. (2010). Users of the world, unite!, The challenges and opportunities of Social Media, Business Horizons, Vol. 1, No. 53, pp. 59-68.

[10] O’ Reilly, T. (2006). Web 2.0 Compact Definition: Traying Again, Radar. Available from http://radar.oreilly.com/2006/12/web-20-compact-definition-tryi.html, Accessed on: 2017-08-27

[11] Badea, M. (2014). Social media and organizational communication, Procedia - Social and behavioural sciences, No. 149 , pp. 70-75.

[12] Kane, G. C. (2017). The evolutionary implications of social media for organizational knowledge management. Information and organization, Vol. 1, No. 27, pp. 37-46. 